\title{
Interactive comment on "A Nonparametric Statistical Technique for Combining Global Precipitation Datasets: Development and Hydrological Evaluation over the Iberian Peninsula” by Md Abul Ehsan Bhuiyan et al.
}

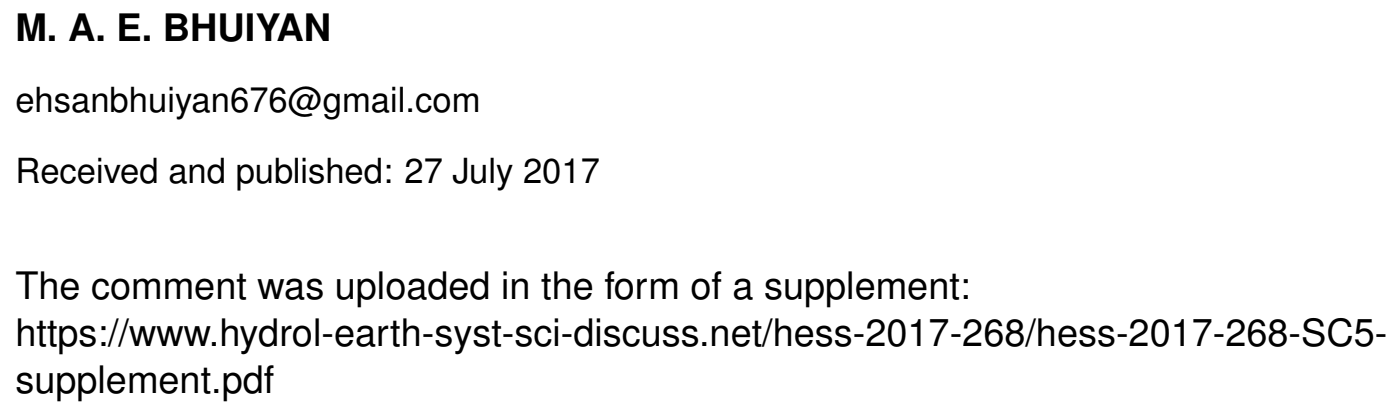

